\title{
La dudosa tentación de la subsidiariedad territorial como principio orientador del proceso descentralizador chileno
}

\section{The dubious temptation of territorial subsidiarity as a guiding prin- ciple of the Chilean decentralization process}

\section{Benoît Delooz Brochet * (D) https://orcid.org/0000-0002-5775-5629}

*Universidad Autónoma, Santiago, Chile. Académico. Docteur en Droit public , U. Toulouse 1 Capitole. @benoit.delooz@uautonoma.cl

(cc) BY

\section{Resumen:}

El objetivo es demostrar, a la luz de ejemplos de derecho comparado, que la consagración del principio de subsidiariedad en materia territorial conduce, en general, a un reforzamiento del poder central y a una recentralización normativa, o al riesgo de un gobierno de los jueces constitucionales en materia de organización políticoadministrativa. En este contexto, el reconocimiento de poderes implícitos en beneficio de los entes territoriales aparece como una alternativa adecuada.

Palabras Clave: Subsidiariedad; Descentralización; Repartición de competencias; Poderes implícitos.

\begin{abstract}
:
The object is to show, in the light of examples of comparative law, that the enshrinement of the principle of subsidiarity in territorial matters generally leads to a strengthening of central power and a recentralization of regulations, or to the risk of a government of constitutional judges in the matter of political-administrative organization. In this context, the recognition of implicit powers for the benefit of local authorities appears as an adequate alternative.

Keywords: Subsidiarity; Decentralization; Division of powers; Implicit powers.
\end{abstract}


La dudosa tentación de la subsidiariedad territorial como principio orientador del proceso...

\section{Introducción}

Como la centralización, la descentralización plena no existe pues, "la descentralización y la centralización totales son sólo polos ideales. Hay un cierto mínimum al cual no puede descender la centralización, y un cierto máximum que la descentralización no puede rebasar sin que se produzca la disolución de la comunidad jurídica" (Kelsen, 1949, p.322). Ahora bien, el grado de descentralización es función, primero, de las normas - y las materias sobre las cuales tratan- que pueden adoptar los órganos centrales y no centrales respectivamente; luego, de la libertad que tienen esos diferentes entes para adoptarlas y, finalmente, de las garantías de dichos entes. El concepto de competencias - materiales y normativas- se vuelve entonces indisociable de una reflexión sobre la noción de subsidiariedad tan de moda hoy en día. Chile no escapa a la "tentación de la subsidiariedad", pues la Comisión Asesora Presidencial en Descentralización y Desarrollo Regional (2014, pp, 29, 36-38) recomienda en varias oportunidades la consagración del principio de subsidiariedad territorial. En lo particular, se señala que "cada función pública debe radicarse en aquel nivel donde ésta se ejerce igual o mejor, privilegiando el nivel local sobre el regional, y éste sobre el nacional. Ello implica que sólo aquellas funciones que no pueden ser asumidas adecuadamente por el nivel local o regional deben recaer en la competencia del gobierno central" (Comisión Asesora Presidencial en Descentralización y Desarrollo Regional, 2014, p. 17). Luego de lo cual afirma que este principio ha sido "exitosamente aplicado con rango constitucional en diversos países hoy descentralizados y desarrollados". Tal aseveración parece algo perentorio, por lo que resulta útil y necesario examinar algunas experiencias extranjeras, antes de querer consagrarlo constitucionalmente.

Para ello, luego de una aproximación general al concepto de subsidiariedad territorial (1), lo estudiaremos desde el punto de vista de la repartición de competencias (2), del ejercicio de las competencias (3) y de su control (4). Los obstáculos para su implantación en Chile (5) conducen a proponer alguna solución alternativa (6).

\section{Aproximación al concepto de subsidiariedad territorial}

La subsidiariedad no es de fácil aprensión. Por una parte, por su evolución histórica ${ }^{1} \mathrm{y}$, por otra, por su asociación con otros conceptos igualmente potentes como los de autonomía o de solidaridad (Millon-Delsol, 1992), lo que explica su éxito, pues todos los ordenamientos jurídicos contemporáneos pretenden fomentar estas últimas. Su traducción política y jurídica es dificultada por el hecho de que "entraña dos implicaciones bastante diferentes, casi opuestas, que se encuentran además en su

\footnotetext{
1 Son referencias obligatorias las siguientes que han precedido o preparado la concepción católica: Aristóteles (1989); Aquino (2010); Althusius (1995); Hobbes (2009) y Locke (2004).
} 
etimología latina" (Delcamp, 1995, p. 614). Estas tienen que ver por una parte con la idea de suplencia, de secundario, de menos importante $y$, por otra, con la de socorro e implica la noción de intervención. No se trata solo de medir si la autoridad tiene el derecho de intervenir, sino también si tiene el deber de hacerlo.

Esa distinción corresponde hoy a las expresiones de subsidiariedad "positiva» y «negativa». La primera consiste en un deber de injerencia de la instancia en caso de carencia de la autoridad inferior; la segunda apunta a limitar la intervención de la instancia superior para dejar a la(s) persona(s) o a la instancia inferior todas las posibilidades de actuar, de manera que se exprese su autonomía. En este último caso, la idea de suplencia se acopla con la no injerencia, para volverse una ayuda que permite la autonomía, de modo que, incluso, puede ser una obligación de la autoridad superior actuar con respecto a la persona, o a la colectividad inferior, de manera tal que pueda realizar su autonomía (Delors, 1991, pp. 8 y 9).

En un sentido general, la subsidiariedad puede ser entendida como una barrera protectora de los poderes de los entes inferiores, o al contrario, como una extensión de los campos de competencia del nivel superior al reforzar sus poderes en nombre de consideraciones de eficacia y de interés común (Sidjanski, 1992, p. 303). Sin embargo, como se ha señalado, conviene distinguir la noción y el principio de subsidiariedad: la primera designa generalmente el socorro, la ayuda, la suplencia, y puede tener significados diferentes, mientras que el principio de subsidiariedad se refiere a la repartición y al ejercicio de las competencias según los diferentes entes o comunidades que existen en un conjunto más grande (Barrué-Belou, 2014, pp. 226 y ss.).

Más allá de una noción general o vaga (Real Academia Española, 2014)², la subsidiariedad es también un principio, en el sentido de "norma o idea fundamental que rige el pensamiento o la conducta" (Real Academia Española, 2014) ${ }^{3}$. Sus manifestaciones las más evidentes tienen que ver con la organización social ${ }^{4}$, con las actividades económicas ${ }^{5}$ o con el ejercicio de atribuciones y funciones de los entes territoriales. Ese último aspecto es objeto del presente trabajo.

\footnotetext{
2 El primer sentido que da el Diccionario de la lengua española a la palabra "noción" es "conocimiento o idea que se tiene de algo", ver en: https://dle.rae.es/noción

${ }^{3}$ Acepción sexta que le da el Diccionario de la lengua española, véase https://dle.rae.es/principio

${ }^{4}$ Como es conocido, ese concepto de organización social es regularmente asociado al pensamiento católico y particularmente a la Carta Encíclica Quadragesimo anno de su Santidad Pío XI sobre la restauración del orden social en perfecta conformidad con la ley evangélica al celebrarse el $40^{\circ}$ aniversario de la encíclica "rerum novarum" de León XIII.

${ }^{5}$ Concepción preponderante o privilegiada en Chile. Se puede consultar la bibliografía citada en los artículos de Loo Gutiérrez (2009) y Vallejo Garretón y Pardow Lorenzo (2008). Ver también: Fermandois Vöhringer (2006); García-Huidobro (1997).
}

Rev. derecho (Coquimbo, En línea) 2019, 26: e3895 
La dudosa tentación de la subsidiariedad territorial como principio orientador del proceso...

La subsidiariedad territorial puede abarcarse en función del ámbito de competencias donde la acción se va a desarrollar. Se presentará entonces como un principio organizacional que estipula que cada nivel de poder solo debe disponer de las competencias que mejor puede ejercer. En ese sentido, puede tomar diversas formas (Delcamp,1995, p. 614) ${ }^{6}$.

Una primera aproximación de la subsidiariedad territorial es funcional. Se trata aquí de hacer intervenir una instancia superior para paliar la falta de una autoridad pública en una materia particular. Una segunda forma es más bien procesal, en el sentido de que determina cuándo la primera autoridad es deficiente o cuándo la autoridad superior otorga mejores garantías. Se vincula fuertemente a la pregunta de saber quién va a determinar la capacidad de cada autoridad, y al control de la amplitud de la intervención de la autoridad superior, lo que la relaciona con el principio de proporcionalidad. En fin, la subsidiariedad territorial se refiere a la intervención de la autoridad superior desde un punto de vista espacial. La autoridad superior debe tener un ámbito de competencias más extendido que la autoridad inferior.

\section{El principio de subsidiariedad y la repartición de las competencias}

Presentado generalmente como principio nuclear de los sistemas federales, "el principio de subsidiariedad", más que una norma jurídica, en teoría puede ser empleado para un Estado unitario descentralizado o por cualquier otra forma (Jackson, 2012, p. 8), es decir, no es propio de un tipo de Estado7.

El federalismo debe ser distinguido de la subsidiariedad. A tal punto, que "las Constituciones federales, en particular, tan preocupadas habitualmente por los principios de articulación de los poderes y de distribución de las competencias, no retienen el término. Alemania, Austria, Bélgica, Brasil ${ }^{8}$, Canadá ${ }^{9}$ Estados Unidos de América ${ }^{10}$, Sui-

\footnotetext{
${ }^{6}$ Citando la obra Die Rechtliche Verbuidlich. Keit des Subsidiaritäts prinzip, de H. K. Kallbrenne.

${ }^{7}$ Contrariamente a lo que afirman varios autores. En la doctrina nacional, ver por ejemplo Loo Gutié$\operatorname{rrez}(2009$, p. 406).

${ }^{8}$ La Constitución brasileña no establece jerarquía entre las comunas, los Estados y la Unión que reciben sus competencias de la Carta fundamental misma, lo que milita en contra del reconocimiento de un principio de subsidiariedad. Ahora bien, los poderes políticos y las capacidades financieras de la Unión la sitúan jerárquicamente por encima de los Estados y de las comunas, como se verá a continuación.

${ }^{9}$ El término es ajeno al derecho positivo canadiense, y es en la aplicación de las reglas relativas a las competencias de cada orden de gobierno que se lo podrá identificar. Así el federal puede en ciertos casos intervenir en ámbitos que no son de su competencia (Rocher y Rouillard 1998).

${ }^{10}$ Para varios autores estadounidenses, la subsidiariedad es una noción ajena a su cultura. La repartición de competencias entre un gobierno federal y Estados federados conduce a que las personas estén sometidas al mismo tiempo a la autoridad de estos dos niveles de gobierno. Cada uno actúa en la esfera de competencia definida por la Constitución. Es que el federalismo, definido como una separación o equilibrio vertical de los poderes, no admite una supremacía predeterminada del nivel federal
} 
za...el recuento es rápido. En ningún lugar, el término subsidiariedad tiene derecho de entrada" (Delperee, 2000, p. 16). En cuanto a los Estados unitarios - caso que nos interesa más aquí por la comparación con Chile - la situación es dispar. Mientras que la Constitución Colombiana (1991, arts. 288 y 356 ) menciona bien el principio de subsidiariedad, pero no como un principio que gobierna la distribución de competencia, sino que gobierna el ejercicio de las competencias atribuidas, el caso francés, contrariamente a lo que se podría pensar, no consagra el principio de subsidiariedad. Es solo un objetivo con valor constitucional cuya persecución puede ser "ahora facilitada por la posibilidad abierta por el artículo 37-1, puesto que las experimentaciones previstas por este artículo permitirán determinar eficazmente el nivel adecuado para el ejercicio de tal o cual competencia" (Viguier, 2013, p. 45), o aún por diversas disposiciones constitucionales, como la libre administración, el recurso a la experimentación, la prohibición de la tutela entre colectividades, la colectividad líder (chef de file) o aun la autonomía financiera, que son objetos de una jurisprudencia del Conseil constitutionnel que permite poco a poco dibujar sus contornos.

Respecto al Estado autonómico español, la Constitución tampoco lo consagra formalmente, pues la última frase del artículo 149.3 enuncia que "el derecho estatal será, en todo caso, supletorio del derecho de las Comunidades Autónomas". Al respecto, la doctrina mayoritaria habla de principio de supletoriedad, y "estima que se trata de una regla de conflicto de competencias y no de una norma de atribución de competencias" (Esteban y Esteban, 2009, p. 59; Lasagabaster Herrarte, 1991, pp. 62 y 95; García de Enterría y Fernández Rodríguez, 1997, p. 334; Carbonell Porras, 1997, p. 195).

Por su lado, la Constitución italiana (1948, art. 118), sí lo menciona, pero, primero, solo se refiere a las competencias administrativas - lo que no implica ninguna garantía- y, luego, una vez más se aplica al ejercicio de las competencias, no a su repartición.

Para terminar esta aproximación relativa a las formas de Estado, podemos señalar que las nuevas formas de Estados plurinacionales, como Bolivia o Ecuador, sí lo reconocen en lo que concierne a los capítulos relativos a la organización territorial. Pero, la formulación del art. 270 de la Constitución Política del Estado plurinacional de Bolivia (2009) es nebulosa y su aplicación parece por lo menos complicada. La Constitución de la República del Ecuador (2008, art. 238, 268, 269 incs. 3 y 4, 270) menciona cinco veces el principio, pero como regulador de las competencias, no como repartidor.

En lo que concierne a la Unión europea, el Tratado de Lisboa (2007) reconoce expresamente por primera vez, que el principio de subsidiariedad se aplica a nivel euro-

sobre los Estados federados. Ahora, si el principio no existe como tal, la idea de subsidiariedad se manifiesta, pero bajo la idea de reequilibrio, de reajuste de los poderes y de las competencias entre las diferentes esferas de gobierno. Para todo ver Barrué-Belou (2014) y la bibliografía citada. 
La dudosa tentación de la subsidiariedad territorial como principio orientador del proceso...

peo, nacional, regional y local, e incluso individual. Desde entonces, es objeto de una ordenación normativa y técnica, pero solo se trata de una versión de dicho principio. A este respecto, es preciso recordar que el principio de subsidiariedad se enuncia en el art. 5 del Tratado de Niza (Unión Europea, 2003), y se concreta en el Protocolo N. 2 sobre la aplicación de los principios de subsidiariedad y de proporcionalidad, anexo al Tratado, al tenor del cual la Comunidad intervendrá en los ámbitos que no sean de su competencia exclusiva, solo en la medida en que los objetivos de la acción pretendida no puedan ser alcanzados de manera suficiente por los Estados miembros, y, por consiguiente, puedan lograrse mejor, debido a la dimensión o a los efectos de la acción contemplada, a nivel comunitario. Así el Tratado de Niza tampoco utiliza el principio para fijar y repartir las competencias entre la Unión y los Estados miembros. Solo organiza y determina el ejercicio de las competencias que no le pertenecen como propias (Constantinesco, 1991, pp. 40-41) ${ }^{11}$. El Tratado de Lisboa (2007) incluye una clasificación de las competencias de la Unión, la definición y enumeración de cada una de ellas y los principios que informan su delimitación y ejercicio. Con este propósito, el Tratado de Niza regula los fundamentos del sistema: "La delimitación de las competencias de la Unión se rige por el principio de atribución. El ejercicio de las competencias de la Unión se rige por los principios de subsidiariedad y proporcionalidad" (Unión Europea, 2003, art, 5 cons. 1). No parece entonces recomendable, como lo hace la Comisión Asesora Presidencial en Descentralización y Desarrollo Regional (2014), "radicar - en nombre de la subsidiariedad cada función pública (...) en aquel nivel donde ésta se ejerce igual o mejor, privilegiando el nivel local sobre el regional, y éste sobre el nacional" (p. 17), porque no es un principio de atribución o repartición de las competencias normativas.

Más, los principios, "son normas que ordenan que algo sea realizado en la mayor medida posible, de acuerdo con las posibilidades fácticas y jurídicas. Por ello, los principios son mandatos de optimización. Como tales, se caracterizan porque pueden ser cumplidos en diferentes grados y porque la medida de cumplimiento ordenada depende no sólo de las posibilidades fácticas, sino también de las posibilidades jurídicas" (Alexy, 2008, p. 14) ${ }^{12}$. Ahora bien, si se consagrará un principio constitucional de subsidiariedad, éste podría constituir un "presupuesto de validez y eficacia de las demás normas integrantes del orden jurídico, y en esa medida [tendría] la capacidad de imponer límites a la actuación de los demás órganos constituidos e irradiar todo el orden jurídico constitucional e infraconstitucional" (Arbeláez Naranjo', 2005). Pero, El alcance del principio

\footnotetext{
${ }^{11}$ Dentro de las razones que han guiado el dibujo institucional del principio de subsidiariedad tomaron importancia la voluntad de los Estados de protegerse contra eventuales pérdidas de soberanía, ilustradas en particular por el paso de la unanimidad a la mayoría calificada en ciertos ámbitos, y entonces aceptar someterse a la decisión a pesar de su oposición.

${ }^{12}$ Ver también: Alexy (2001).
} 
de autonomía cumple ya esa función ${ }^{13}$ y no parece necesario inscribir un nuevo principio en la Carta fundamental.

Además, la constitucionalización de una repartición de competencias materiales va en contra de la naturaleza unitaria del Estado, tal como es entendida tradicionalmente en Chile, donde son los colegisladores -representantes de la soberanía nacional- que adaptan la estructura territorial y reparten las competencias normativas de índole administrativo entre los diferentes entes territoriales. $Y$ no parece razonable, dejar al juez constitucional decidir en último término de la administración territorial del país.

\section{El principio de subsidiariedad y el ejercicio de las competencias}

La primera de las cuestiones concierne a la competencia de principio. El término es generalmente utilizado por los Estados federales o regionales, pero puede aplicarse al Estado unitario y lo es de modo regular bajo el nombre de competencia general. La teoría jurídica quiere que la competencia de principio pertenezca en general a entidades distintas del gobierno federal o el Estado central, en la medida que son competentes para todo lo que no ha sido atribuido a este último. En el Estado unitario, esa cuestión fundamental no presenta normalmente problemas. Por definición, en ausencia de normas constitucionales que otorgan competencia sobre una materia a un nivel territorial particular, esa potestad corresponde al Estado. La competencia general implica la existencia de competencias de atribución, a menos de encontrarse en un caso de centralización total, lo que -como se ha visto -no existe, ni históricamente ni teóricamente. Las competencias de atribución se dividen a su vez en competencias exclusivas, competencias compartidas y concurrentes. Es justamente en el ámbito de esas dos últimas que suele afirmarse que puede jugar un papel el principio de subsidiariedad. Pero, en realidad se aplica a todo tipo de competencias. Veamos algunos ejemplos que lo demuestran.

En la Unión Europea, el principio de subsidiariedad solo se aplica a las "competencias compartidas" con la Unión, que debe demostrar cuando quiere legislar, que "los objetivos de la acción pretendida no puedan ser alcanzados de manera suficiente por los Estados miembros, ni a nivel central ni a nivel regional y local, sino que puedan alcanzarse mejor, debido a la dimensión o a los efectos de la acción pretendida, a escala de la Unión" (Unión Europea, 2003, art, 5, cons. 3).

Aplicada al ámbito de las competencias concurrentes, la subsidiariedad permite una actualización de las intervenciones de la Federación o del Estado federal

\footnotetext{
${ }^{13}$ Ver el desarrollo del 4.2, más abajo, sobre los criterios de control jurisdiccional de la aplicación del principio de subsidiariedad.
} 
La dudosa tentación de la subsidiariedad territorial como principio orientador del proceso...

cuando actúa con el objetivo de obtener un mejor resultado que cada Estado considerado de manera aislada.

El caso de Alemania es interesante en este ámbito porque operó una reforma constitucional para romper con el llamado "Estado Federal unitario" (Hesse, 1984), es decir la evolución hacia una alianza entre federalismo y descentralización. Para invertir el desvío centralista, la revisión en 1994 de la Ley Fundamental de la República Federal Alemana buscó reequilibrar el federalismo alemán, y reescribió el artículo 72 inc. 2 relativo al capítulo "VII. Legislación de la Federación", poniendo énfasis en las dos dimensiones del principio de subsidiariedad (Ley Fundamental de la República Federal Alemana, 1949, art. 72, inc. 1) ${ }^{14}$, pues "la Federación tiene la competencia legislativa, si y en la medida que sea necesaria una regulación legislativa federal en interés de la totalidad del Estado para la creación de condiciones de vida equivalentes en el territorio federal o el mantenimiento de la unidad jurídica o económica" (Ley Fundamental de la República Federal Alemana, 1949, art. 72, inc. 2) ${ }^{15}$

La subsidiariedad aparece también claramente en el ámbito de las competencias concurrentes de la Unión federal en Brasil, pues la Constitución en su artículo 24 señala que "compete a la Unión, a los Estados y al Distrito Federal legislar concurrentemente sobre" (1988, art. 24) una lista de dieciséis materias. Pero, quizás lo más relevante son los cuatro numerales que terminan ese artículo al mencionar que "10. En el ámbito de la legislación concurrente, la competencia de la unión se limitará a establecer normas generales. $2^{\circ}$. La competencia de la Unión para legislar sobre normas generales no excluye la competencia suplementaria de los Estados. $3^{\circ}$. No existiendo la ley federal sobre aspectos generales, los Estados ejercerán la competencia legislativa plena, para atender a sus peculiaridades. $4^{\circ}$. La sobrevivencia de una ley federal sobre aspectos generales suspende la eficacia de la ley estatal, en le fuese contraria". La subsidiariedad en beneficio de la Unión se manifiesta también -como en los otros Estados federales- en el ámbito fiscal. Así, el artículo 153 enumera las materias fiscales reservadas a la Unión y el artículo 155 los impuestos de los Estados. Pero, el artículo 154-1 señala que "la Unión podrá establecer: 1. mediante ley complementaria, los impuestos no previstos en el artículo anterior".

\footnotetext{
${ }^{14}$ Para aproximarse a la problemática alemana, se debe también considerar el art. 30.

${ }^{15}$ Como se ha señalado, "es cierto que el acceso del Bund a la técnica de la legislación concurrente fue dificultado, por cuanto en el futuro no le bastara para legislar la mera "necesidad" de dictar una norma federal para garantizar la igualdad jurídica y económica o el establecimiento de condiciones de vida equivalentes en el ámbito federal, sino que tal norma federal debería ser "imprescindible" para lograr la consecución de dichos fines" (Schneider, 2009, p. 16).
} 
También, se debe tener presente que la Constitución brasileña establece una lista de doce materias calificadas de "competencia común de la Unión, de los Estados, de Distrito Federal y de los Municipios" (1988, art. 23). Ello permite entonces dar aplicación al principio de subsidiariedad en su vertiente descendiente y ascendiente, al menos teóricamente.

La subsidiariedad puede también manifestarse en el caso de las competencias exclusivas. Así en Brasil, prevé que es competencia de los Municipios "legislar sobre asuntos de interés local" (Constitución de la República Federativa del Brasil, 1988, art. 30, n. 1) también les corresponde "suplementar la legislación federal y estatal en lo que cupiese" (Constitución de la República Federativa del Brasil, 1988, art. 30, n. 2). En Canadá, el Acta constitucional de $1867^{16}$ instauró una organización de la federación que invierte el esquema clásico del federalismo, puesto que otorga una atribución general a la Unión para actuar de manera de "asegurar la paz, el orden y el buen gobierno" (The Constitution Act, 1867, art. 91) le. El mismo artículo establece también una lista de competencias enumeradas en beneficio de la Federación y el artículo 92 contiene la lista de las competencias exclusivas de las Provincias. De esa manera, a la inversa del sistema federal clásico que supone la competencia general (o de principio) en beneficio de los Estados federados, en Canadá es la federación que goza de tal poder. De tal suerte que el sistema federal canadiense puede ser calificado de "centralizado" y permite a la Federación -como se verá a continuación- intervenir incluso en materias exclusivas de las Provincias.

Por último, la voluntad de determinar ámbitos claros de competencias para cada nivel de gobierno no debe confundirse con la voluntad de proteger las competencias de los entes inferiores mediante el principio de subsidiariedad. Ese no puede ser su rol. La subsidiariedad, en la medida que acepta la intervención de una instancia superior en caso de fallo o incapacidad del ente inferior (como en el caso de los Estados federales o con tendencia federativa), tiende a legitimar la injerencia de la instancia superior.

A modo ejemplar, en el sistema federal estadounidense, es conocida la jurisprudencia de la Corte Suprema de los EE.UU. justificando el incremento de los poderes federales en desmedro de los poderes de los Estados federados. A partir de su decisión McCulloch vs. Maryland (1819), la Corte permitió al Congreso, sobre la base de la "cláusula final" y de la "cláusula del comercio", utilizar la teoría de los poderes implicados (implied powers) que le reconoce la libre elección de los medios para llevar a cabo los fines que la Constitución le asigna e intervenir así en los asuntos de los Estados federados. En Canadá, la complejidad de las fuentes del derecho constitucional y, particularmente, la interpretación del párrafo introductorio del artículo 91 de la Ley

\footnotetext{
${ }^{16}$ Anteriormente conocida como Acte de l'Amérique du Nord britannique o The British North America Act Rev. derecho (Coquimbo, En línea) 2019, 26: e3895
} 
La dudosa tentación de la subsidiariedad territorial como principio orientador del proceso...

constitucional de 1867 condujo a incrementar de manera considerable los poderes del gobierno federal al consagrar la existencia de una competencia residual federal, una teoría de los poderes de urgencia (The Judicial Committee of the Privy Council Decisions, 1923, AC 695) o la teoría de las dimensiones nacionales (The Judicial Committee of the Privy Council Decisions, 1882, UKPC 33, 7 App Cas 829). Del mismo modo, la segunda frase de dicho párrafo, Ilamada cláusula "declaratoria" permite identificar la teoría de la preponderancia o, aún, la teoría de la usurpación (empiétement $)^{17}$, en beneficio de la federación.

Tratándose de un Estado no federal, los casos de Italia o Colombia son reveladores.

En Italia, la Corte constitucional introdujo el principio de subsidiariedad normalmente reservado al ejercicio de las funciones administrativas ${ }^{18}$ - dentro de los mecanismos de repartición de las competencias legislativas (Morrone, 2003), desarrollando una jurisprudencia favorable al nivel estatal. Cabe señalar que, ya incluso respecto de las funciones administrativas, el artículo 120 inc. 2 establece una cláusula de sustitución del Estado ${ }^{19}$ de los entes territoriales, cuyas condiciones se asemejan a las fijadas, por ejemplo, por la Corte Constitucional alemana o la Corte Suprema de Canadá.

En Colombia, a pesar de los artículos 288 y 356 de la Constitución ya citados, la Corte Constitucional ha señalado que:

"el legislador, en ejercicio de su potestad de configuración, se desplaza para fijar el grado de autonomía en cada materia o asunto a cargo de las entidades territoriales.

Este es el significado de la expresión contenida en el artículo 287 de la Constitución Política, según la cual 'Las entidades territoriales gozan de autonomía para la gestión de sus intereses, y dentro de los límites de la Constitución y la ley'"' (Corte Constitucional de Colombia, 2001, C-1258/01, cons. 7).

\footnotetext{
${ }^{17}$ Por todo, Barrué-Belou (2013) y las referencias jurisprudenciales allí citadas.

${ }^{18}$ La Constitución Italiana distingue en su artículo 117, inc. 6, las disposiciones relativas al poder reglamentario y las administrativas en artículo 118.

19 "Podrá el Gobierno suplir a los órganos de las Regiones, Urbes metropolitanas, Provincias y Municipios en caso de inobservancia de normas y tratados internacionales o de la normativa comunitaria o bien de peligro grave para la incolumidad y seguridad pública, o cuando así lo exija la preservación de la unidad jurídica o económica y en particular la salvaguardia de los niveles básicos de las prestaciones relativas a derechos civiles y sociales, sin tomar en consideración para ello los límites territoriales de los órganos de gobierno local. Se establecerán por ley procedimientos destinados a garantizar que los poderes sustitutivos se ejerzan con observancia del principio de subsidiariedad y del de colaboración leal."
} 
Un caso aparte lo constituye España, donde el Tribunal Constitucional "no dudó en aniquilar el principio de subsidiariedad del derecho estatal" (Esteban y Esteban, 2009 , p. 58 $)^{20}$ en beneficio de las Comunidades Autónomas.

\section{El difícil control de la aplicación del principio de subsidiariedad}

El control que se ejerce sobre el ente superior que pretende intervenir en algunos ámbitos de competencias de un ente inferior puede obedecer a diversos criterios. Puede tratarse primero, del momento de la intervención, es decir a qué momento se estima que el ente inferior ya no tiene la capacidad de actuar solo de manera satisfactoria. Luego, se plantea el control de la amplitud de la intervención: en ese caso se refiere en definitiva al principio de proporcionalidad. Por último, se presenta el tema del ámbito de la intervención, es decir sobre qué tipo de competencias.

Sobre este último punto, salvo el caso preciso ya mencionado de la Unión Europea (competencias compartidas), hemos visto que todas las competencias pueden estar concernidas. Sobre los dos primeros criterios, en realidad es difícil distinguirlos. La práctica es entonces más instructiva que el intento de teorización y, por ello, se debe distinguir el control político del jurisdiccional.

\subsection{Modalidades de control político}

Puesto que el principio de subsidiariedad es fundamentalmente político, su control es antes que nada, tarea de los diferentes parlamentos. De manera general, existen mecanismos propios de los sistemas federales clásicos donde el Senado como cámara representante de los Estados federados dispone de minoría de bloqueo en contra de las usurpaciones por parte del gobierno federal. Muy a menudo, el problema se desplaza sobre el terreno de la ley de presupuesto.

Para los Estados unitarios, el control parlamentario mediante la votación de la ley de presupuesto constituye, también, un control previo de las intervenciones del Estado central y la repartición de las competencias. Permite fijar los límites de la acción presupuestaria de cada ente territorial. Luego, se pueden mencionar las diferentes comisiones administrativas o parlamentarias que realizan estudios de impacto previo o evaluación expost. Finalmente, toman relevancia los procedimientos de experimentación de traspasos o de "repatriación" de competencias, como lo permite la Constitución Política Chilena (1980, art. 114).

En el caso de la Unión europea es conocido el "mecanismo de alarma temprana" previsto en el "protocolo sobre la aplicación de los principios de subsidiariedad y proporcionalidad". Así la Unión debe someterse a un "test de eficacia comparativa"

${ }^{20}$ N.d.R : Traducción del autor.

Rev. derecho (Coquimbo, En línea) 2019, 26: e3895 
La dudosa tentación de la subsidiariedad territorial como principio orientador del proceso...

(Delcamp, 1995) ${ }^{21}$, al "principio de proporcionalidad" (Delcamp, 1995) 22 y, por último, a mecanismos de control engorrosos por parte de los Parlamentos nacionales, e incluso, regionales.

\subsection{Criterios de control jurisdiccional}

No existe un criterio único y universal del control jurisdiccional. Así, encontraremos varias denominaciones o principios. ¿Quién es competente para decidir qué tal o cual autoridad ya no tiene la capacidad de cumplir sus funciones, y que el bien común exige la intervención de la autoridad superior? El control remite entonces a esa apreciación (Rocher y Rouillard, 1998, p. 242) como al grado o amplitud de intervención, es decir aplicando el principio de proporcionalidad o del error manifiesto de apreciación, por citar algunos ejemplos (Isaac y Blanquett, 2001, p. 48; Bermann, 1994, pp. 377, 386-390, 401 y 4379. Como se ha señalado, el principio de proporcionalidad es "el más importante principio del derecho constitucional material" (Alexy, 2008 , p. 15) y contiene los tres subprincipios de idoneidad, necesidad y proporcionalidad en sentido estricto. Los dos primeros subprincipios de idoneidad y de necesidad "expresan el mandato de optimización relativo a las posibilidades fácticas. En ellos la ponderación no juega ningún papel. Se trata de impedir ciertas intervenciones en los derechos fundamentales, que sean evitables sin costo para otros principios. Ahora bien, el principio de proporcionalidad en sentido estricto se refiere a la optimización relativa a las posibilidades jurídicas" (Alexy, 2008, p. 15).

En ese sentido, parecería que la Corte Constitucional Federal alemana hizo aplicación de la dicotomía entre principios y reglas al operar un giro jurisprudencial (BVerfG, 24.10.2002, 2 BvF 1/01) en 2002, en cuanto al alcance de la "cláusula de necesidad". A partir de entonces, controla al legislador federal sobre la base de las dos condiciones establecidas por el art. 72 inc. 2 LF$^{23}$, a saber, "la creación de condiciones

\footnotetext{
${ }^{21}$ Lo cual implica la consideración de varios elementos propios de la UE: "efecto de escala, costo de la inacción, necesidad de mantener una coherencia razonable, límites de una acción aislada a nivel nacional, necesidad de respetar las reglas de competencia. El test de eficacia comparativa debe demostrar el "valor añadido" que podría resultar de la intervención" (pp. 619-620) (N.d.R. Traducción de autor).

${ }^{22}$ Que demanda que, a un nivel de igual eficacia, se escoja la intervención que permite la mayor libertad; luego, evitar que una acción indispensable se traduzca en un exceso de reglamentación; y en fin, privilegiar la claridad y concisión de las normas-

${ }^{23} \mathrm{~A}$ partir de esa fecha, los Landers usaron de manera importante el recurso previsto al art. 93, inc. 2, №2 LF según el cual "la Corte Constitucional Federal decide además a petición del Bundesrat, de un Gobierno de un Land o de la Asamblea legislativa de un Land, si en caso del artículo 72, apartado 4 no subsiste la necesidad de una regulación por ley federal según el artículo 72, apartado 2". Por ejemplo: BVerfG (24.10.2002, 2 BvF 1/01, cons 148 y ss.) relativa a ley federal de asistencia a la tercera edad; BVerfG (27.07.2004, 2 BvF 2/02): relativa a normas federales en materia de universidades como la relativa a los catedráticos júnior (Juniorprofessur); BVerfG (26.01.2005, 2 BvF 1/03): relativa a las tasas académicas; BVerfGE (16.03.2004, 1 BvR 1778/01) sobre la ley federal de protección de animales. Todas ellas fueron llevadas ante el TCF para que las enjuiciara, y los criterios favorables a los Landers establecidos por la
} 
de vida equivalentes en el territorio federal" y "el mantenimiento de la unidad jurídica o económica".

En ese contexto, el legislador federal puede intervenir en nombre del principio de subsidariedad cuando se presenta al menos uno de los siguientes criterios (o reglas en sentido de Alexy): que se esté en presencia de un desarrollo desigual de las condiciones de vida en los Lander que perjudique - o pueda perjudicar- gravemente el tejido social federal (BVerfG, 24.10.2002, 2 BvF 1/01, cons. 144); que sea necesario evitar la diversidad legislativa entre los Lander si representa una división, estallido jurídico con consecuencias problemáticas para el Bund como para los Lander (BVerfG, 24.10.2002, 2 BvF 1/01, cons. 145); o, en fin, cuando solo la dictación de una reglamentación federal única permite la preservación de la funcionalidad del espacio económico de la República federal (BVerfG, 24.10.2002, 2 BvF 1/0, cons. 146). La conjunción de esas condiciones y criterios permitiría dar vida al principio de subsidiarie$\mathrm{dad}^{24}$ en su doble dimensión que es, a la vez, su doble requisito: la dimensión de socorro -que los Lander no sean más capaces de cumplir sus misiones- y la dimensión de reserva -que la intervención federal se limite a lo estrictamente necesario. El caso de Canadá se asemeja en lo que concierne a las condiciones de intervención del Gobierno federal (Barrue-Belou, 2014, p. 244), pero los tribunales son más timoratos. Ya sea que se trate de la teoría de los intereses nacionales (Barrue-Belou, 2014, p. 244) o

Corte Constitucional Federal, obligó al Bund a adoptar la reforma constitucional de 2006, cuantitativamente la más importante desde 1949. Esto modificó el mismo inc. 2 de ese artículo relativo a la legislación concurrente de la Federación. Hoy, su competencia legislativa es limitada a "las materias del artículo 74, apartados 1 nos 4, 7, 11, 13, 15, 19 a, 20, 22, 25 y 26", es decir principalmente al sector económico y social, al derecho de los extranjeros, la propiedad colectiva, la responsabilidad del Estado federal, la bioética, la salud y la salubridad pública. Pero, por razonamiento sensu contrario, el Bund es competente para todas las otras materias sin necesidad de justificar su intervención, lo que favorece una recentralización de varias competencias concurrentes.

${ }^{24} \mathrm{El}$ reemplazo del Estado de derecho legislativo (o legal) por el Estado constitucional llevó consigo una separación que implica precisar lo que uno entiende por regla y por principio, ambos normas configurando el Derecho actual. Gustavo Zagrebelsky en El derecho dúctil. Ley, derechos, justicia plantea que las normas legislativas son reglas, mientras que las normas constitucionales sobre derechos y sobre la justicia son prevalentemente principios, y por ello, distinguir entre reglas y principios significa en gran medida distinguir la Constitución de la ley, este autor, saca varias consecuencias dentro de las cuales, la primera que nos interesa aquí es que sólo a las reglas se aplican los métodos de interpretación jurídica que analizan el lenguaje del legislador. Los principios tendrían un sentido, tal vez muy amplio, pero entendidos en su ethos por el conjunto de la sociedad. Explicando más allá la distinción, Zagrebelsky (2003, p. 110) usa la formula siguiente que no es sino recordar la de Alexy: "a las reglas 'se obedece' $y$, por ello, es importante determinar con precisión los preceptos que el legislador establece (...); a los principios, en cambio, 'se presta adhesión' y, por ello, es importante comprender el mundo de valores, las grandes opciones de cultura jurídica de las que forman parte". Sin embargo, como se señalará más adelante, el problema reside siempre en el riesgo del gobierno de los jueces constitucionales que serían mejores intérpretes que los colegisladores para determinar cuándo es necesario intervenir y cuando no. 
La dudosa tentación de la subsidiariedad territorial como principio orientador del proceso...

de la cláusula declaratoria, los tribunales se niegan a controlar la oportunidad de esa apropiación de competencia por parte del nivel federal.

En lo que concierne a algunos Estados no federales, el control se limitará al error manifiesto de apreciación (Francia), al núcleo esencial o a la aplicación del principio de cooperación leal, dando lugar a un control errático que permite siempre advertir el riesgo de un gobierno de los jueces constitucionales.

El Conseil Constitutionnel (2005, 2005-516 DC, cons. 102) cerró la puerta provisoriamente a la aplicación de un eventual principio de subsidiariedad, puesto que en la decisión del 7 de julio de 2005, reconoció que el legislador disponía de cierto margen de apreciación para la definición de las zonas de desarrollo de la energía eólica en atención al interés general. En este sentido, conforme a la Carta Europea de la Autonomía Local (1985, art. 4, n. 3) el legislador define la amplitud y la naturaleza de las tareas confiadas a las colectividades territoriales tomando en cuenta las exigencias de eficacia y de economía. El artículo 72 inc. 2 traduce, a fin de cuentas, solo "una visión tecnocrática de la repartición de las competencias, operada sin tener a la vista los intereses de los habitantes, pero en función de las características propias de las materias que se deben gestionar, y en función de consideraciones que tienen que ver con sus modalidades de gestión" (Bénoit, 2006, p. 36). Entonces, puede leerse de otra manera de cómo lo hace parte de la doctrina: no consagraría el principio de subsidiariedad a favor de las colectividades territoriales, sino una libertad de apreciación más grande del legislador (Fraisse, 2005, pp. 21-22) 25. En efecto, es él quien determinará el conjunto de las competencias que mejor pueden ser aplicadas a sus diferentes niveles. El Conseil constitutionnel bien parece validar esa interpretación, pues está dispuesto a censurar al legislador solo en caso de error manifiesto (Conseil Constitutionnel, 2005, 2005-516 DC, cons. 12 y 13). ${ }^{26}$

Seguramente, la Constitución enuncia una regla de fondo que limita el poder discrecional del legislador, pero el juez constitucional ya lo controlaba por referencia a la libre administración, es decir, la autonomía en derecho chileno. Además, "contrariamente a lo que sugiere la referencia a la subsidiariedad, la regla de fondo así formula-

\footnotetext{
${ }^{25}$ Afirma primero que la decisión (de 2005 evocada) del Conseil constitutionnel es clara : «le deuxième alinéa de l'article 72 de la Constitution énonce un principe et non un objectif à valeur constitutionnelle; ce principe a une portée normative ; il signifie qu'il appartient au législateur de confier l'exercice d'une compétence à la collectivité qui, eu égard aux caractéristiques de cette compétence et aux intérêts concernés, est le mieux à même de l'exercer ». Pero, luego debe admitir que «toutefois, le caractère peu contraignant des termes utilisés par le constituant lui laisse une grande marge d'appréciation; en conséquence, son choix ne saurait être remis en cause par le Conseil constitutionnel qu'en cas d'erreur manifeste ».

${ }^{26}$ Además, el Conseil constitutionnel estima que ese principio no es un derecho o una libertad que la Constitución garantiza, y que pueda ser invocado en el marco de una cuestión prioritaria de constitucionalidad. No pertenece entonces a los derechos constitucionales de las colectividades territoriales, lo que contribuye a darle un aspecto esencialmente mágico (Éveillard, 2013, p. 26-32).
} 
da no tiene necesariamente un alcance descentralizador: debido a ciertas exigencias tales como la igualdad entre los ciudadanos, el análisis podría también concluir la elección del nivel nacional o regional con preferencia al nivel local" (Douence, 2013). De considerar que aquello es subsidiariedad, se puede sostener que el principio ya tenía una traducción en los hechos y en los textos legislativos que consagran la diversidad y la especificidad de los estatutos o recursos acordados ${ }^{27}$.

En lo relativo a la teoría del núcleo esencial, este es vinculado a la idea de garantías institucionales. Al respecto, cabe señalar que la comprensión chilena actual de la autonomía municipal deriva directamente de la noción de garantía institucional importada del derecho español (Tribunal Constitucional español, 1981, 32/1981, cons. 3), el cual a su vez la recogió de la doctrina y jurisprudencia alemana ${ }^{28}$. Ahora bien, la teoría de las garantías institucionales se apoya sobre un "núcleo esencial" casi imposible de encontrar (Carro Fernández-Valmayor, 2000, pp. 557 y ss.) ${ }^{29}$ Sobre ese punto, el Tribunal Constitucional chileno ha señalado que la autonomía constitucionalmente reconocida a ciertos órganos o entes, se proyecta en tres dimensiones: organizacional, institucional y normativa. (Tribunal Constitucional, 1989, 80-89). Pero no se sabe muy bien hasta donde van esos límites, puesto que es el legislador quien les configura. En ese sentido, la Corte Constitucional colombiana ha justamente señalado que "el legislador está autorizado para fijar los alcances de la autonomía territorial, dentro de los límites mínimos y máximos que señala la Constitución -en un extremo, el núcleo esencial, y en el otro, el límite dado por el carácter unitario del Estado-, los cuales no podrá sobrepasar" (Corte Constitucional de Colombia, 2001, C-1258/01, cons. 7). En definitiva, la garantía institucional "solo es el derecho para los entes territoriales de existir administrativamente y de actuar cuando existe un interés local" (Esteban y Esteban, 2009, p. 53).

En fin, podemos señalar el caso de Italia donde la Corte Constitucional estimó que cuando el Estado central quiere atraer - sobre la base del principio de subsidiariedad- las competencias legislativas regionales, lo deberá hacer de manera propor-

\footnotetext{
${ }^{27}$ Así, del estatuto de los territorios de ultramar (especificidad geográfica y cultural) y el de los casos particulares de Paris-Lyon-Marsella (especificidad demográfica) o de Córcega (especificidad cultural). Eso se aplica hoy en principio al conjunto de las colectividades territoriales, pero está sobre todo consagrado en práctica por la adopción del artículo 72 inc. 5 que recoge las nociones de acción común y de líder (chef de file).

${ }^{28} \mathrm{El}$ Tribunal Constitucional español señala, la primera vez que utilizó la noción de garantía institucional (que además fue respecto de la autonomía local) que: "Por definición, en consecuencia, la garantía institucional no asegura un contenido concreto o un ámbito competencial determinado y fijado de una vez por todas, sino la preservación de una institución en términos reconocibles para la imagen que de la misma tiene la conciencia social en cada tiempo y lugar."

${ }^{29}$ La doctrina alemana intentó definir el contenido esencial de la garantía institucional, sin realmente lograrlo. Su influencia sobre el derecho español ha sido subrayada. Para un resumen de los esfuerzos de la doctrina alemana, los conceptos y las técnicas de protección que propuso, y su recepción por la jurisprudencia constitucional española.
}

Rev. derecho (Coquimbo, En línea) 2019, 26: e3895 
La dudosa tentación de la subsidiariedad territorial como principio orientador del proceso...

cional, razonable y privilegiando la asociación de las regiones en nombre del principio de cooperación leal. Pero esa asociación es de alcance variable, según los ámbitos de intervención (Biglione, 2009, p. 140).

\section{Los obstáculos para la aplicación del principio de subsidiariedad territorial en Chile}

Las disposiciones de la Constitución Política de la República de Chile (1980) tradicionalmente citadas para referirse al principio de subsidiariedad son los artículos 1 , inc. 2 y art. 3. El art. $1^{\circ}$ se refiere únicamente a los cuerpos intermedios en el ámbito económico. De la lectura de la historia de la elaboración del art. 3 de la Constitución Política de la República de Chile, se encuentra una referencia al principio de subsidiariedad. En efecto, durante la sesión N. 16 del 13 de noviembre de 1973, J. Guzmán había notado "la importancia de consagrar el principio de la descentralización del Poder o de la 'subsidiariedad', entendiendo que la función del Estado es, en primera instancia, la de integrar y coordinar las diversas actividades del país, y sólo, en subsidio, y en segunda instancia, la de asumir en forma directa una tarea específica, cuando, por su importancia, no pueda ser entregada a la órbita de los cuerpos intermedios" (Biblioteca del Congreso Nacional, 2005).

En materia territorial, la Constitución Política de la República de Chile no consagra una repartición de las competencias ya sean exclusivas y/o concurrentes. Luego, la aplicación del principio de subsidiariedad sobre el modelo europeo parece difícil, tanto política como jurídicamente, porque no se concibe al gobierno central sometiéndose a los mismos controles que la Unión Europea.

Hoy todavía, el principio no es reconocido, ni por el derecho positivo, ni por la jurisprudencia chilena como elemento estructurante de la distribución de las competencias territoriales. Solo se aplica, según la jurisprudencia del TC, a los particulares ya sea personalmente, o reagrupados en cuerpos intermedios (Tribunal Constitucional, 2002, 352-02, cons. 7), lo que es una aplicación a priori conforme con la idea primera y católica del principio (Pío XI, 1931). Se podría inferir que una municipalidad o una región es un ente territorial que reagrupa individuos, y sugerir, entonces, una aplicación del principio de subsidiariedad. Pero, el TC precisó que "las agrupaciones intermedias son todas las asociaciones distintas al aparato público, es decir, todas aquellas que no sean órganos del Estado en todas sus manifestaciones, esto es, órganos de la Administración del Estado, tribunales, órganos autónomos, corporaciones de derecho público" (Tribunal Constitucional, 2009, 1295-08, cons. 55). Ahora bien, las regiones y las municipalidades son organismos administrativos que integran el aparato público. 
Se trata una vez más de una lectura parcial y torcida del principio por parte del TC. En efecto, la Encíclica «Quadragesimo anno» señalaba también que "como no se puede quitar a los individuos y dar a la comunidad lo que ellos pueden realizar con su propio esfuerzo e industria, así tampoco es justo (...) quitar a las comunidades menores e inferiores lo que ellas pueden hacer y proporcionar y dárselo a una sociedad mayor y más elevada" (Pío XI, 1931). Nada en la expresión "comunidades menores e inferiores" permite descartar los agrupamientos de derecho público, sobre todo, que los entes territoriales son colectividades o comunidades, y ello permitiría instaurar al lado de una "subsidiariedad horizontal", una "subsidiariedad vertical"30. Si se revela difícil revisar la Constitución Política de la República de Chile en beneficio de los entes territoriales, el principio de subsidiariedad podría eventualmente aplicarse, si el juez constitucional y el legislador fueran consecuentes con el reconocimiento de la existencia de competencias privativas en beneficio de las municipalidades. En fin, el principio podría aplicarse en el marco del Convenio 169 de la ONU relativo a los pueblos indígenas que obliga el Estado chileno a consultar todos los componentes étnicos reconocidos como tales, para cualquier proyecto de ley que les concierne.

\section{Una alternativa a la subsidiariedad territorial como garantía de una descentralización efectiva: el reconocimiento de poderes implí- citos en beneficio de los entes inferiores}

En los Estados unitarios, la noción de competencia implícita puede sustituir de manera satisfactoria la fascinación que ejerce el principio de subsidiariedad, en la medida en que el gobierno central tolere ciertas iniciativas de los entes territoriales no previstas de manera expresa por las diferentes normas. En caso de duda sobre el titular de una competencia - porque las normas pueden ser contradictorias, borrosas o presentar un vacío jurídico - ¿Quién de entre dos agentes (o más) tiene el derecho o debe ejercer tal actividad, o dictar tal acto jurídico? No es solamente una cuestión teórica. Al contrario, el problema de la competencia general en el Estado unitario interroga de una manera más fuerte que en otro lugar la cuestión de las competencias implícitas de las colectividades infraestatales.

\subsection{La noción de competencias implícitas}

La noción de competencias implícitas remite en general a la historia del incremento de los poderes del gobierno federal de los Estados Unidos. En una federación de Estados o Estado federal, tal como es entendido comúnmente (Zoller, 2002) ${ }^{31}$, a diferencia de lo que acontece en un Estado unitario, no es el gobierno central el que dispone de la plenitud y de la exclusividad de la competencia, sino el con-

\footnotetext{
${ }^{30}$ La subsidiariedad horizontal se aplica respecto de los ciudadanos y de las organizaciones sociales. Ver, por ej., los arts. 118 inc. 3 y 4 de la Constitución italiana.

${ }^{31}$ Para una crítica de la teoría continental europea del "Estado federal".
} 
La dudosa tentación de la subsidiariedad territorial como principio orientador del proceso...

junto de las entidades gobierno federal-Estados miembros que la ejercen de manera compartida. Es decir, el gobierno federal no puede reducir a los Estados al estatuto de entes descentralizados por la extensión unilateral de su potestad (o de sus competencias). Sin embargo, los Estados federales tienen tendencia a la centralización o a centralizar las competencias, y eso, contra el texto de la Constitución federal. La teoría de las competencias implícitas aplicada a la teoría del Estado federal permite justificar movimientos centrípetos de competencias de los Estados federados hacia el gobierno federal. Parece entonces inadecuado referirse a la noción de competencias implícitas, en lo que concierne a las relaciones Estado unitario-entes territoriales. El Estado tiene por definición el monopolio de todos los poderes, y es solo porque lo quiere, que consiente en hacer ejercer una parte de aquellos por parte de entes territoriales que él mismo crea, o reconoce en su seno. Sin embargo, conviene resituar el debate: el Estado federal, como el Estado unitario, son tipos-ideales weberianos, a partir del momento en que están constituidos de:

"una serie de acontecimientos construidos por el pensamiento que se vuelven a encontrar muy raramente con la pureza ideal en la realidad empírica y a menudo nunca, pero por otro lado, como sus elementos están tomados de la experiencia y solamente acentuados por el pensamiento hasta lo racional, sirven tanto de medios heurísticos al análisis como de medios constructivos a la exposición de la diversidad empírica" (Weber, 1992, pp. 396-397).

En los Estados unitarios descentralizados, el vacío o el silencio a veces dejado por el legislador para aplicar la ley y/o la necesidad de hacerse cargo de una actividad, cuando el interés general de la comunidad local lo exige, dejan lugar al ejercicio de competencias implícitas de parte de los entes territoriales. El Estado y los diferentes niveles de administración territorial están encargados, cada uno en lo que le concierne, de la representación del conjunto de los intereses colectivos de los habitantes de sus respectivas circunscripciones. Si la competencia implícita no fluye directa y forzosamente de la autonomía de los entes territoriales, eliminarla consistiría en negarla, comprendida esta como otra cosa que la simple ejecución de las disposiciones legales. Es, por lo demás, en este sentido que la Carta Europea de la Autonomía Local (1985, art. 4, n. 2) entiende la libertad de actuar de las colectividades locales "dentro del ámbito de la Ley ${ }^{32}$, [como] libertad plena para ejercer su iniciativa en toda materia que no esté excluida de su competencia o atribuida a otra autoridad".

La afirmación de la existencia de una competencia implícita está más bien relacionada con la existencia misma de entes territoriales diferentes del Estado y con

\footnotetext{
${ }^{32}$ Lo que hay que entender como "en los límites de la Legalidad (o juridicidad)" en sentido amplio y como "insertado en los límites estrictos de las leyes de descentralización".
} 
sus naturalezas corporativas. Sería inherente a la idea de comunidad ${ }^{33}$. Seguramente no se puede decir que los entes dispondrían por naturaleza de ciertas competencias, pero a la inversa es difícil negar que una comunidad tenga vocación para hacerse cargo de las necesidades de sus miembros ${ }^{34}$. En ese sentido, el reconocimiento de competencias implícitas, salvo prohibición legal expresa, puede ser una solución frente al temor de algunos de consagrar o no el principio de subsidiaridad en la Constitución Política de la República de Chile. De hecho, es "evocada" de una cierta manera directamente por la Constitución Política de la República de Chile para las regiones y municipalidades, sobre todo, para esas últimas calificadas de corporaciones autónomas de derecho público. ${ }^{35}$ El problema para los entes chilenos reside en el artículo 7 de la Constitución Política de la República de Chile que consagra la atribución expresa de competencia so pena de nulidad. Ante tal rigidez, el TC tuvo la oportunidad de precisar que

"tratándose de la potestad reglamentaria municipal, sin embargo, es necesario considerar que tiene que existir un espacio para los intereses municipales en la complementación o ejecución de la legislación. En ese sentido, la ley debe regular nacionalmente, pero con una uniformidad básica o esencial. El elemento normativo uniforme o común del legislador nacional debe ser, por lo mismo, no especialmente detallado. Por una parte, porque no puede no considerar las realidades diferentes de cada municipio. Las casi 350 municipalidades que existen en nuestro país no son iguales. Tienen diferencias geográficas, de clima, de realidad económica, de densidad poblacional" (Tribunal Constitucional, 2012, 1669-10, cons. 56).

Parece entonces que la competencia implícita es inevitable: cubre, por definición, el conjunto de las competencias que son susceptibles de ejercer las colectividades territoriales, particularmente en ámbitos que aún no existen o que no están aún reglamentados. Y no hay razones para inquietarse por eso.

\footnotetext{
${ }^{33}$ Es por eso que es más fácilmente reconocida a las municipalidades en cuánto célula de base de la vida pública (incluso pre-estatal) y que está otorgada o negada a los entes creados por el Estado.

${ }^{34}$ Una cosa es reconocer que no hay esfera de intervención que escape al Estado, y otra reconocer que en ausencia de Estado o de interdicción del Estado - constitucional, legal u otra - una colectividad local tiene o tendría una vocación general a hacerse cargo de las actividades que estime necesarias. Es un hecho histórico, sociológico y antropológico. Es el sentido de las dos primeras frases de la Política de Aristóteles (1989).

${ }^{35}$ El artículo 111 inc. 2 relativo a la región declara que "el gobierno regional tendrá por objeto el desarroIlo social, cultural y económico de la región" y el artículo 118 inc. 3 que "las municipalidades son corporaciones autónomas de derecho público, con personalidad jurídica y patrimonio propio, cuya finalidad es satisfacer las necesidades de la comunidad local y asegurar su participación en el progreso económico, social y cultural de la comuna".
}

Rev. derecho (Coquimbo, En línea) 2019, 26: e3895 
La dudosa tentación de la subsidiariedad territorial como principio orientador del proceso...

\subsection{La teoría de los poderes implícitos y la consagración de la noción de cláusula general de competencia}

La aplicación de la teoría de los poderes implícitos permite justificar el poder reglamentario territorial por una habilitación normativa general, la cláusula general de competencia - como se la llama en Francia, que le da, si no su fuerza, por lo menos un carácter de evidencia (Conseil d'Etat,1990, 84898) ${ }^{36}$. Su exposición puede ser de interés para Chile.

En efecto, "se admite la existencia de una competencia implícita cuando la autoridad de ejecución está autorizada a adoptar todas las medidas que implica una buena y completa ejecución de la ley sin haber sido invitada explícitamente por ella a hacerlo. De tal manera que, si estos poderes no son formalmente incluidos en los términos de la habilitación legal, sin embargo, ya lo están implícitamente" (Faure, 2011, p. 543).

Ligada a los poderes necesarios para el cumplimiento de su misión, encuentra su origen jurisprudencial en Francia en las jurisprudencias Jamart (Conseil d'Etat, 1936, 43321) de 1936 y Dehaene de 1950 (Conseil d'Etat, 1950, 01645), aunque se pueda, cronológicamente, relacionarla con la jurisprudencia anterior relativa al "socialismo municipal" (Conseil d'Etat, 1930, 06781) e incluso, antes (Conseil d'Etat, 1901, 94580).

Esta extensión del poder reglamentario territorial se explicaría por las razones siguientes: primero, ciertas funciones atribuidas a las autoridades locales comportarían el otorgamiento implícito de un poder reglamentario, como es el caso para cualquier autoridad ejecutiva en Francia - y en una institución en general - al título del poder de policía. En efecto, el poder de policía, responsable de "un cierto orden en la Polis (...) hace esencialmente parte de la competencia natural del poder ejecutivo" (Teitgen, 1934, pp. 1 y ss.).

Luego, está admitido que la norma que encarga a una autoridad la ejecución de deliberaciones de un organismo colegial confiere implícitamente a dicho ejecutivo el derecho de dictar los reglamentos de ejecución de dichas deliberaciones ${ }^{37}$.

En fin, por extensión de la jurisprudencia Jamart, la autoridad ejecutiva local, como jefe de servicio, puede adoptar reglamentos para la organización y el funcionamiento interno de los servicios ${ }^{38}$ cuando el reglamento nacional no lo haya hecho Conseil d'Etat, 1985, 40756) ${ }^{39}$. Se notará que las leyes orgánicas chilenas relativas a las

\footnotetext{
${ }^{36}$ Para Francia, el Conseil d'État reconoció a las colectividades territoriales un verdadero "pouvoir réglementaire local spontané dans l'application des lois".

${ }^{37}$ El Conseil d'État francés admite esa solución desde hace bastante tiempo para el alcalde, sea sobre petición del consejo municipal o espontáneamente (Rouault, 1991, p. 127).

${ }^{38}$ Puede así reglamentar los horarios de atención de los servicios municipales, el ejercicio del derecho a huelga del personal municipal, etc.

${ }^{39} \mathrm{Si}$ una ley no remite a un decreto de aplicación, "pertenece entonces al órgano de la colectividad local,
} 
regiones y a las municipalidades prevén esa intervención del gobernador regional y del alcalde. Faure, estimando que "la aplicación de esa teoría hace que no exista vacío jurídico en derecho de las colectividades territoriales" (Faure, 2011, p. 543), menciona dos ejemplos; uno que tiene que ver con la organización interna de las colectividades (Conseil d'Etat, 1985, 40756) ${ }^{40}$, el otro ligado a una verdadera acción externa (Conseil d'Etat, 1972, 81486) ${ }^{41}$. J. Auby (1992), reconoció ya hace veinticinco años que "en ausencia de una ley, las autoridades locales pueden adoptar reglamentos"42. Si es verdad que esas palabras estaban escritas en el marco de una reflexión sobre el origen legislativo o constitucional del poder reglamentario territorial, el cambio constitucional de 2003 no afecta la justeza de la afirmación, puesto que esta intervención "inicial" es solo provisoria y debe situarse en el marco de las leyes cuando intervienen.

Parte de la doctrina chilena va en el mismo sentido. Así, a la cuestión ¿Puede una autoridad administrativa dotada de potestad reglamentaria dictar normas reglamentarias, aunque no haya ley cuya aplicación se trata de proveer?, P. Aylwin Azócar contesta: "entre nosotros se ha entendido que el Presidente de la República puede hacerlo, siempre, eso sí, que no contradiga una ley, ni invada materias propias de ley. Dentro de estas limitaciones, "no se discute la discrecionalidad" que puede asumir el contenido de un reglamento" (Aylwin Azocar, 1959, p. 45).

Incluso más allá de alguna referencia a un ámbito reservado de los reglamentos, Silva Cimma afirma que:

"la potestad reglamentaria en nuestro país es mucho más amplia que el simple papel de mecanismo ejecutor de la ley, y determinada en su alcance por la misión esencial de administrar el Estado que se le encomienda al Presidente de la República, ella se extiende aun a los casos no legislados, siempre naturalmente que no se atente contra los principios esenciales y fundamentales que consagra la Constitución, y-como es natural- siempre también que ella no vaya en contra de ley expresa" (Silva Cimma, 1968, pp. 215-216) ${ }^{43}$.

Estos dos autores refutan entonces la necesidad y la posibilidad absoluta de encuadrar de manera preventiva el ejercicio del poder reglamentario, como lo afirman algunos sobre la base de los artículos 6 y 7 de la Constitución. Tal posición va en contra de la necesaria adaptabilidad y mutabilidad del servicio público.

Ahora bien, Silva Cimma destaca que:

competente para organizar los servicios de esa colectividad, fijar las reglas de aplicación" de aquella.

${ }^{40}$ A propósito de la aptitud de las comunas y sus agrupaciones para determinar las reglas de organización y funcionamiento de los comités de higiene y seguridad que la ley les encomendaba, pero sin precisar las condiciones de instalación.

${ }^{41}$ La construcción de una piscina en aplicación - implícita - de una ley sobre las instalaciones necesarias para la enseñanza parvularia, no es contraria a la libertad de negocio e industria.

42 N.d.R. Traducción del autor.

${ }^{43}$ Véase además: Silva Bascuñán (1963, p. 260). 
La dudosa tentación de la subsidiariedad territorial como principio orientador del proceso...

"la potestad reglamentaria municipal es restringida, pues la Constitución y la ley se han encargado de precisar detalladamente las materias en que ella debe recaer. En otras palabras, a diferencia de la potestad reglamentaria del Presidente de la República que (...) se extiende al amplio campo de la actividad discrecional, los municipios sólo tienen una potestad limitada, es decir, se produce en el orden de las actividades regladas, o sea, con el carácter de ejecutora de la ley (...) el legislador ha sido en esto consecuente con el principio de que mientras al Presidente de la República le entrega la administración del Estado en general, a los Municipios les confía sólo la administración local de cada Comuna o agrupación de comunas"(Silva Cimma, 1968, p. 152).

La posición de ese autor no obsta a la existencia de la cláusula general de competencia. Primero, como las comunas francesas, las municipalidades tienen atribuciones limitadas y enmarcadas por las leyes. Luego, se podría completar la afirmación de la manera siguiente: si el Presidente de la República está a cargo de la administración del Estado en general, las Municipalidades tienen a su vez, de una cierta manera, la administración local en general de cada comuna o agrupamiento de comunas y pueden entonces adoptar los actos normativos necesarios a las necesidades de la comunidad local. Quizás los tiempos nuevos permitirán entender que:

"Una Administración que no actúa no es ya una Administración que no daña sino una que no actualiza, que no ejecuta, que no optimiza los bienes sociales para alcanzar el desarrollo de nuestro proyecto común (...)

Debe también superarse el paradigma de la predeterminación normativa que menosprecia una programación finalista y que presupone una completa regulación de los poderes administrativos. Repetido ad nauseam es el aforismo que expresa que en el Derecho Público puede hacerse sólo lo que está permitido por la ley, lo que refleja una cierta limitación y desconfianza en la regulación administrativa asumiendo que los escenarios desregulados son 'naturalmente' más amigables para el ciudadano o que aquella normación administrativa es anormal en el programa político y social de una comunidad. Por el contrario, un Derecho Administrativo que pretenda dar respuestas ciudadanas y cuyo objetivo sea la construcción de un programa de vida social con fines determinados debe interpretarse y definirse a la luz de esos fines sin más trabas formales que aquellas con las cuales se asegura legitimidad" (Letelier Wartenbeg, 2014).

En definitiva, la afirmación siguiente podría aplicarse al orden jurídico chileno: "la cláusula general y el principio de especialidad tienden, si no a confundirse, por lo menos a articularse: la cláusula de competencia nunca es completamente general, la especialidad de la legislación no encierra completamente la acción local. Pero, mientras la 
primera lectura es dinámica, la segunda es estática y descriptiva. En los dos casos, la acción local no está definida por la colectividad, pero sí por el Estado que fija la competencia" (Doat, 2003, p. 215). De tal modo que la renovación del principio de subsidiariedad ha podido dar la idea a algunos de justificar la existencia de una competencia general sobre la base de su aplicación.

\section{Conclusiones}

A modo de conclusión, podemos señalar que:

1. El principio de subsidiariedad no es un principio de atribución de competencias.

2. El principio de subsidiariedad se manifiesta en el ejercicio de todos los tipos de competencia.

3. El principio de subsidiariedad en realidad refuerza el poder central.

Seguramente, algunos Estados han inscrito el principio de subsidiariedad en sus Constituciones, pero su aplicación se traduce generalmente en una recentralización de las competencias de los entes territoriales (las épocas de crisis económica favorecen este fenómeno) que son, además, regularmente solo competencias administrativas y de atribución. En definitiva, frente a la pusilanimidad bien comprensible de las Cortes constitucionales o de las diferentes Cortes supremas, no parece que se pueda escapar de la necesidad de reforzar el control político.

Complejo y ambiguo, el principio de subsidiariedad puede ser útil en términos funcionales de eficacia, o de economías de escala, o en términos "democráticos", para acercar el poder de decisión al ciudadano, pero la subsidiariedad no es ni un principio centralizador, ni descentralizador. Puede llevar a uno como al otro tipo de organización. Es un principio dinámico que describe el equilibrio de las fuerzas presentes y los objetivos de los responsables de los entes que participan en el sistema. No resulta entonces determinante consagrar constitucionalmente el principio de subsidiariedad.

Entonces, en los Estados unitarios como Chile, que no prevén una repartición constitucional de competencias materiales, el lugar dado a un eventual principio de subsidiariedad servirá a lo más como instrumento de medición del grado de descentralización otorgado por el Estado central. Es decir, será contingente y no estructural. En rigor, es un principio que puede inspirar al legislador, pero no se le puede imponer: "más que una norma que definiría, el principio de subsidiariedad indica una tendencia. Deja abiertas las condiciones concretas de su aplicación y estas pueden 
La dudosa tentación de la subsidiariedad territorial como principio orientador del proceso...

entonces variar según las condiciones de tiempo y de lugar" (Delcamp, 1995, p. 621) ${ }^{44}$. Por ello, el principio de subsidiariedad territorial presentado por la Comisión Asesora Presidencial (2014), corresponde a un deseo piadoso de otorgar más competencias a los entes territoriales inferiores, no al perfilamiento de un sistema más descentralizado ${ }^{45}$. Esa verdad aparece en el hecho de que, en el Estado unitario, es el gobierno central que otorga, y lo que da con una mano, lo puede siempre recuperar con la otra. En las otras formas de Estado, el principio de subsidiariedad no sirve para repartir las competencias, sino para modular y adaptar una repartición ya establecida. En definitiva, cualquiera sea su calificación, la misma idea permanece: la de mayor eficiencia para resolver un problema.

\section{Agradecimientos}

Este trabajo forma parte del proyecto de investigación FONDECYT Iniciación No 11160082, del cual el autor es investigador responsable.

\section{Referencias Bibliográficas}

Acción de inaplicabilidad por inconstitucionalidad de Energía Limarí S.A. respecto de los artículos 5 c) y 12 del DFL No 1/2006 del Ministerio del Interior, 15, 124 y 221 del DFL No 4/20.018, de 2006, del Ministerio de Economía Fomento y Reconstrucción, en los autos Rol No 5678-2008 sobre recurso de casación en el fondo interpuesto ante la Corte Suprema, 1669-10 (Tribunal constitucional 15 de marzo de 2012). https://bit.ly/34dCvsy

Alemania Federal. (1949). Ley Fundamental para la República Federal de Alemania. Recuperado de https://bit.ly/2PhRdu1

Alexy, R. (2001). Teoria de los Derechos Fundamentales. (E. Garzón Valdés, Trad.). Madrid: Centro de estudios políticos y constitucionales.

Alexy, R. (2008). La fórmula del peso. En M. Carbonell Sánchez (Ed.), El principio de proporcionalidad y la interpretación constitucional (pp. 13-42). Quito: Ministerio de justicia y derechos humanos. Recuperado de https://bit.ly/2EaqxW2

Althusius, J. (1995). Politica. (F. S. Carney, Trad.). Indianapolis: Liberty Fund Inc. Recuperado de https://bit.ly/2RI8zCg

Aquino, T. de. (2010). Suma teológica II (R. Suárez, Trad.). Madrid: Biblioteca de autores cristianos.

\footnotetext{
${ }^{44}$ N.d.R. Traducción del autor.

${ }^{45}$ Contrariamente a lo que afirma una parte de la doctrina. Por ejemplo: Quintana Benavides (2014).
} 
Arbeláez Naranjo, G. (2005). El ordenamiento territorial: instrumento para la gobernabilidad. Opinión jurídica, 4(7), 125-138. Recuperado de https://bit.ly/2LM2Ya0

Aristóteles (1989). Política. (J. Marías y M. Araujo Fernández, Trads.). Madrid : Centro de estudios constitucionales.

Auby, J. (1992). Décentralisation et sources du droit. Actualité juridique. Edition droit administratif, (Spécial). 30-34.

Aylwin Azocar, P. (1959). Apuntes de derecho administrativo (Vol. 1). Santiago: Universitaria.

Barrué-Belou, R. (2014). Analyse des outils fédératifs aux États-Unis, au Canada et au Brésil : contribution à l'étude du fédéralisme (Thèse de doctorat). Université Laval. Recuperado de https://bit.ly/35mr2bq

Bénoit, F. P. (2006). L'évolution des affaires locales. De la décentralisation des autorités à la décentralisation des compétences. En P. Bon (Coord.). La profondeur du droit local. Mélanges en I'honneur de Jean-Claude Douence (pp. 23-43). Paris: Dalloz.

Bermann, G. A. (1994). Taking subsidiarity seriously: federalism in the european community and the united states. Columbia law review, 94(2), 331-456. https://doi.org/10.2307/1123200.

Biblioteca del Congreso Nacional (2005). Historia del Artículo 3 de la Constitución Política de la República de Chile. Recuperado de https://bit.ly/38FR8YM

Biglione, F. (2009). Le régionalisme italien, bilan et perspectives. En F. Brisson (Dir.). Les transferts de compétences de l'État aux collectivités locales (pp.129-157). Paris: L'Harmattan.

Bolivia (2009). Constitución Política del Estado plurinacional de Bolivia. Recuperado de https://bit.ly/2M6MrOP

Brasil (1988). Constitución de la República Federativa del Brasil. Recuperado de https://bit.ly/2YLodhr

Canadá (1867). The Constitution Act. Recuperado de https://bit.ly/2rOCXQy

Carbonell Porras, E. (1997). La supletoriedad del derecho estatal en la reciente jurisprudencia constitucional. Revista de administración pública, (143), 189-210. Recuperado de https://bit.ly/2E9HvUh

Carro Fernández-Valmayor, J. (2000). El debate sobre la autonomía municipal. En F. Sosa Wagner (Coord.). El derecho administrativo en el umbral del siglo xxi: homenaje al profesor Dr. Don Ramón Martín Mateo (pp. 545-580). Valencia: Tirant lo Blanch.

Casanova, 94580 (Conseil d'Etat, 29 mars 1901). Recuperado de https://bit.ly/35iDBEx Rev. derecho (Coquimbo, En línea) 2019, 26: e3895 
La dudosa tentación de la subsidiariedad territorial como principio orientador del proceso...

Chambre syndicale du commerce en détail de Nevers, 06781(Conseil d'Etat, 30 mai 1930). Recuperado de https://bit.ly/2td4zPT

Charles Russell v The Queen (New Brunswick), UKPC 33, 7 App Cas 829 (The Judicial Committee of the Privy Council Decisions 23 June 1882). Recuperado de https://bit.ly/2YFWFdq

Chile (1980) Constitución Política de la República de Chile. Recuperado de http://bcn.cl/1 uva9

Colombia (1991). Constitución Política de Colombia. Recuperado de https://bit.ly/2LT4Yxc

Comisión Asesora Presidencial en Descentralización y Desarrollo Regional (2014). Propuesta de política de Estado y agenda para la descentralización y el desarrollo territorial de Chile. Hacia un país desarrollado y justo. Recuperado de https://bit.ly/34e5Frt

Consejo Europeo (1985). Carta Europea de la Autonomía Local. Recuperado de https://bit.ly/2PjKi3K

Constantinesco, V. (1991). Le principe de subsidiarité : un passage obligé vers l'Union européenne?. En E. Decaux (Coord.). Mélanges en hommage à Jean Boulouis. L'Europe et le droit (pp. 35-45), Paris: Dalloz.

Contra la Ley de Cataluña 6/1980, de 17 de diciembre, por la que se regula la transferencia urgente y plena de las Diputaciones catalanas a la Generalidad, 32/1981 (Tribunal Constitucional español, 28 de julio de 1981), Recuperado de https://bit.ly/35iUdvQ

Dehaene, 01645 (Conseil d'Etat, 7 juillet 1950). https://bit.ly/36yiL4u

Delcamp, A. (1995). Droit constitutionnel et droit administratif: principe de subsidiarité et décentralisation. Revue françaises de droit constitutionnel, (23), 609-624.

Delors, J. (1991). La subsidiarité - Principe directeur des futures responsabilités en matière de politiques communautaires?. En Subsidiarité : défi du changement: Actes du colloque, (pp. 7-19). Maastricht: Institut européen d'administration publique.

Delperee, F. (2000). Observations liminaires. En su Justice constitutionnnelle et subsidiarité (pp. 11-25). Bruxelles : Bruylant.

Demanda de inconstitucionalidad contra el artículo 49 (parcial) de la Ley 617 de 2000, C1258/01 (Corte Constitucional de Colombia, 29 de noviembre de 2001). https://bit.ly/2YH1fZ3

District urbain du Pays de Montbéliard, 84898 (Conseil d'Etat 31 janvier 1990). Recuperado de https://bit.ly/2PIOoRI 
Doat, M. (2003). Recherches sur la notion de collectivité locale en droit administratif français. París : L.G.D.J.

Douence, J. (2005). Le statut constitutionnel des collectivités territoriales. Encyclopédie dalloz des collectivités locales, 1 (183).

Ecuador (2008). Constitución de la República del Ecuador. Recuperado de https://bit.ly/2LTbKTE

Esteban, E. y Esteban, P. (2009). La régulation par le juge de la répartition des compétences en Espagne. En F. Brisson (Dir.), Les transferts de compétences de l'Etat aux collectivités locales (pp. 45-66). Paris : L'Harmattan.

Éveillard, G. (2013). Intercommunalité et libre administration des collectivités locales. Droit administratif, (8-9), 26-32.

Faure, B. (2011). Droit des collectivités territoriales (2a ed.). Paris : Dalloz.

Fermandois Vöhringer, A. (2006). Derecho constitucional económico, garantías económicas, doctrina y jurisprudencia (2a ed., Vol. 1). Santiago: Editorial Pontificia Universidad Católica de Chile.

Fraisse, R. (2005). Quelle est la portée du principe de subsidiarité?. Droit administratif, (8-9), 21-22.

García de Enterría, E. y Fernández Rodríguez, T. (1997). Curso de derecho administrativo (8a ed., Vol. 1). Madrid: Civitas.

García-Huidobro, J. (1997). Más allá de las modernizaciones, la reconstitución del Estado. Revista chilena de derecho, 24(2), 225-252.

Hesse, K. (1984). Ausgewählte Schriften, Heidelberg: C.F. Müller.

Hobbes, T. (2009). Leviatán o la materia, forma y poder de un estado eclesiástico y civil. (C. Mellizo Cuadrado, Trad.) (11a ed.). Madrid: Alianza.

Isaac, G. y Blanquet, M. (2001). Droit communautaire général (8a ed). Paris: Armand Colin.

Italia (1948). Constitución de la República Italiana. Recuperado de https://bit.ly/2EdLdfF

Jackson, V. (2012). Fédéralisme - Normes et territoires. En M. Troper y D. Chagnollaud (Dirs.), Traité international de droit constitutionnel. (Vol. 2, pp. 6-52). Paris: Dalloz.

Jamart, 43321 (Conseil d'Etat, 7 février 1936). https://bit.ly/2rxEMl4 
La dudosa tentación de la subsidiariedad territorial como principio orientador del proceso...

Kelsen, H. (1949). Teoría general del derecho y del Estado. (E. García Maynez, Trad.). México, D. F.: Imprenta Universitaria.

Lasagabaster Herrarte, I. (1991). Los principios de supletoriedad y prevalencia del derecho estatal respecto al derecho autonómico. Madrid: Civitas.

Letelier Wartenbeg, R. (10 de enero de 2004). La reforma del Derecho Administrativo chileno. De la primacía de la persona humana a la primacía de las personas. Diario Constitucional. Recuperado de https://bit.ly/2RLK1Z4

Locke, J. (2004). Segundo tratado sobre el gobierno civil. (C. Mellizo Cuadrado, Trad.). Madrid: Alianza.

Loi de programme fixant les orientations de la politique énergétique, 2005-516 DC (Conseil Constitutionnel 7 juillet 2005). Recuperado de https://bit.ly/2PkGwaq

Loo Gutiérrez, M. (2009). La disciplina constitucional del principio de subsidiariedad en Italia y Chile. Revista de derecho (Valparaíso), (33), 391-426. http://dx.doi.org/10.4067/S0718-68512009000200011.

Millon-Delsol, C. (1992). L'État subsidiaire. Paris: PUF.

Morrone, A. (2003). La corte costituzionale riscrive il titolo V?. Forum di quaderni costituzionali rassegna, (4), 818-819. Recuperado de https://bit.ly/2E7AeEu

Pío XI. Vaticano II. Carta encíclica Quadragesimo anno. Mayo 15 de 1931. Recuperado de https://bit.ly/2Eh8E7H

Quintana Benavides, A. (2014). El principio de subsidiariedad. Revista de derecho público. (Especial Marzo), 125-136. https://doi.org/10.5354/0719-5249.2014.31682.

Real Academia Española (2014). Diccionario de la lengua española, (23a ed.). Recuperado de https://dle.rae.es

Requerimiento formulado por la Junta de Gobierno en virtud del artículo 82 No 2 de la Constitución, respecto del proyecto de ley que establece normas para resolver las cuestiones de competencia entre autoridades administrativas, 80-89 (Tribunal constitucional 22 de septiembre de 1989). Recuperado de https://bit.ly/2LNiSBa

Requerimiento de inconstitucionalidad presentado por un grupo de Diputados respecto del proyecto de ley que traspasa la dependencia del Liceo Experimental Manuel de Salas desde la Universidad Metropolitana de Ciencias de la Educación a la Universidad de Chile, 352-02 (Tribunal constitucional 15 de julio de 2002), https://bit.ly/38xny7W

Requerimiento de inaplicabilidad por inconstitucionalidad de catorce Compañias de Seguros Generales respecto de los artículos $3^{\circ}$ y $4^{\circ}$ del $D L n^{\circ} 1.757$ de 1977, en recurso de reclamación de que conoce la CA de Santiago, causa rol n 7910-2008, 1295-08 (Tribunal constitucional 6 de octubre de 2009). https://bit.ly/36seGP6 
Rocher, F. y Rouillard, C. (1998). Décentralisation, subsidiarité et néo-libéralisme au Canada: lorsque l'arbre cache la forêt. Canadian public policy, 24(2), 233-258. https://doi.org/10.2307/3551775.

Rouault, M. (1991). L'Intérêt communal. Lille: Presses universitaires de Lille.

Schneider, H. (2009). La reforma del federalismo en Alemania. Fines, negociaciones, resultados. Revista d'estudis autonòmics i federals, (8), 11-36. Recuperado de https://bit.ly/2t9zxs 1

Sidjanski, D. (1992). L'avenir fédéraliste de l'Europe, Paris: PUF.

Silva Bascuñán, A. (1963). Tratado de derecho constitucional (Vol. 3). Santiago: Editorial jurídica de Chile.

Silva Cimma, E. (1968). Derecho administrativo chileno y comparado (Vol. 1). Santiago: Editorial jurídica de Chile.

Société La plage de la forêt, 81486 (Conseil d'Etat, 23 juin 1972). https://bit.ly/36yK1zN

Syndicat communautaire d'aménagement de l'agglomération nouvelle Cergy-Pontoise, 40756 (Conseil d'Etat 13 février1985). Recuperado de https://bit.ly/2PhATd5

Teitgen, P. (1934) La police municipale : étude de l'interprétation jurisprudentielle des articles 91, 94 et 97 de la loi du 5 avril 1884, Paris : Sirey.

The Fort Frances Pulp and Paper Company Limited $v$ The Manitoba Free Press Company Limited and others, AC 695 (The Judicial Committee of the Privy Council Decisions 25 July 1923). Recuperado de https://bit.ly/2rxfZ0u

Unión Europea (2003). Tratado de Niza. Recuperado de https://bit.ly/2tfsdLD

Unión Europea (2007). Tratado de Lisboa. Recuperado de https://bit.ly/38xhbl0

Urteil des Zweiten Senats, 2 BvF 1/01 (BVerfG 24.10.2002). Recuperado de https://bit.ly/2EeFPsL

Urteil des Zweiten Senats, 1 BvR 1778/01 (BVerfG 16.03.2004). Recuperado de https://bit.ly/2YOx8ib

Urteil des Zweiten Senats, 2 BvF 2/02 (BVerfG 27.07.2004). Recuperado de https://bit.ly/2srMU6p

Urteil des Zweiten Senats, 2 BvF 1/03 (BVerfG 26.01.2005). Recuperado de https://bit.ly/36xHHZQ 
La dudosa tentación de la subsidiariedad territorial como principio orientador del proceso...

Vallejo Garretón, R. y Pardow Lorenzo, D. (2008). Derribando mitos sobre el Estado empresario. Revista chilena de derecho, 35, (1), 135 - 156. http://dx.doi.org/10.4067/S0718-34372008000100006.

Viguier, J. (2013). La décentralisation : d'une manière d'être de l'État vers une manière d'être hors de l'État. En S. Regourd, J. Carles, y D. Guignard (Dir.). La décentralisation 30 ans après (pp. 29-57), Toulouse : LGDJ Lextenso.

Weber, M. (1992). Essais sur la théorie de la science. (J. Freund, Trad.). Paris: Agora.

Zagrebelsky, G. (2003). El derecho dúctil. Ley, derechos, justicia. (M. Gascón, Trad.) (5a ed.). Madrid: Trotta.

Zoller, E. (2002). Aspects internationaux du droit constitutionnel : contribution à la théorie de la fédération d'Etats. En Académie de droit international de La Haye (Ed.), Recueil des cours (Vol. 294, pp. 39-166). La Haya: Brill.

\section{Para citar este artículo bajo Norma APA 6a ed. \\ Delooz Brochet, B. (2019). La dudosa tentación de la subsidia- riedad territorial como principio orientador del proceso descen- tralizador chileno. Revista de Derecho (Coquimbo. En línea), 26, e3895. https://doi.org/10.22199/issn.0718-9753-2019-0018.}

Copyright del articulo: (2) 2019. Benoît Delo0z

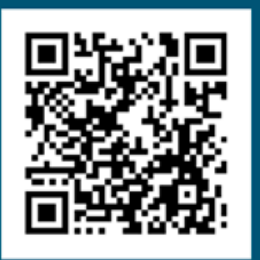

DOI

\section{(c) BY}

Este es un artículo de acceso abierto, bajo licencia Creative Commons BY 4.0. 